\title{
CONSTRUÇÃO SOCIAL DA MULHER: DA RELAÇÃO DE COMPRA AO EMPODERAMENTO
}

\author{
CONSTRUCCIÓN SOCIAL DE LA MUJER: DE LA RELACIÓN DE COMPRA AL EMPODERAMIENTO
}

Mayra Yonara Pereira Barbosa*

\begin{abstract}
RESUMO
As desigualdades entre os sexos são o foco para as relações estabelecidas entre os gêneros; homens e mulheres sempre apresentaram posições distintas no âmbito social e, com isso, foi sendo construída uma forte diferença nas divisões de trabalho, na posição política, na remuneração financeira e no reconhecimento de classe. Em $O$ segundo sexo, Simone de Beauvoir destaca as relações entre homens e mulheres como uma desigualdade tão extrema, que as deixa numa situação de vulnerabilidade. Também Carole Pateman destaca que tal vulnerabilidade minimiza a posição social feminina, ao modo que a mulher é submetida a firmar um contrato de casamento ou sexual. O presente trabalho busca realizar uma reflexão inicial a respeito da construção social feminina, de forma a fazer uma breve análise sobre desigualdade de gênero no viés da "mais valia", na qual, tanto o contrato sexual, quanto o contrato de casamento impõem um valor econômico na mulher e reproduz desvantagens que limitam a sua capacidade de se empoderar.
\end{abstract}

PALAVRAS-CHAVE: Desigualdade. Gênero. Vulnerabilidade. Construção Social. Contrato Sexual.

\section{RESUMEN}

Las desigualdades entre los sexos son el foco de las relaciones establecidas entre géneros, hombres y mujeres siempre han presentado diferentes posiciones en la esfera social, y con esto, se ha construido una gran diferencia en las divisiones de trabajo, en la posición política, en la remuneración financiera y em el reconocimiento de clase. En El Segundo Sexo, Simone de Beauvoir, destaca las relaciones entre hombres y mujeres como una desigualdad tan extrema que los deja en una situación de vulnerabilidad. Al mismo tiempo, Carole Pateman destaca que esta vulnerabilidad minimiza la posición social femenina, en la forma en que la mujer es sometida al acuerdo de un matrimonio o un contrato sexual. El presente trabajo busca llevar a cabo una reflexión inicial sobre la construcción social de las mujeres, con el fin de hacer un breve análisis sobre la desigualdad de género en términos de "plusvalía", en el que tanto el contrato sexual como el contrato matrimonial imponen un valor económico en las mujeres y reproduce desventajas que limitan su capacidad de empoderarse.

PALABRAS CLAVE: Desigualdad. Género. Vulnerabilidad. Construcción social. Contrato sexual.

\footnotetext{
* Graduação em biologia Pela Universidade Federal de Alagoas. Professora na Escola Estadual Rui Barbosa. E-mail: mayra_yonara@hotmail.com.
} 


\section{1 (DES) IGUALDADE ENTRE OS SEXOS}

Ao observar a história das sociedades humanas mais primitivas, percebe-se que sempre existiu uma dualidade entre os gêneros, as mulheres apresentavam funções distintas em relação às dos homens e consideradas incapazes de realizarem as mesmas atividades. Ao longo do tempo, essa premissa atravessou as gerações, e atualmente a desigualdade entre homens e mulheres é marcada fortemente por uma repressão sexista.

Criaram-se estereótipos culturais que transformaram as mulheres em seres subordinados aos homens, e estes classificados como seres superiores e dominantes. Nesse sentido, Simone de Beauvoir (1970, p. 12) indaga: "por qual (ou quais) motivo (s) as mulheres não contestam essa soberania do macho? De onde vem essa submissão da mulher?".

A história é marcada por figuras masculinas, desde a representação histórico-social à força de trabalho utilizada como meios de obtenção de recursos para a subsistência. Com isso, formou-se uma divisão de funções, nas quais as mulheres eram determinadas a realizar funções domésticas, caracterizadas como função de pouca expressão, ficando os homens com aquelas configuradas como meios de sobrevivência. Desse modo, as mulheres tornaram-se dependentes socialmente e culturalmente dos maridos.

Beauvoir (1970) destaca que a desigualdade funcional existente entre os sexos possibilita o não reconhecimento da mulher como sujeito dotado de direitos de igualdade, nos quais questões salariais, oportunidades de emprego e posição política são exemplos da dominação dos homens nos âmbitos sociais que minimizam a participação da mulher, portanto a subordinação feminina tange aspectos não somente fisiológicos, mas também histórico-culturais.

São muitos os exemplos que demonstram a dualidade entre os gêneros, de forma a impor à mulher o estereótipo de "esposa ideal". Porém algumas mudanças foram sendo conquistadas e permitiram uma modificação no panorama social feminino, entre elas, a conquista ao voto por meio do Movimento Sufragista, que imperou uma revolução entre os sexos, e desde então as mulheres começaram a se reconhecer como sujeito de direitos sociais e políticos.

Beauvoir (1970, p. 15) afirma que "existe uma dificuldade para as mulheres fazerem parte da elaboração do mundo. Os laços que unem as mulheres aos homens as tornam um "outro" dentro de uma totalidade, mas um "outro" em sentido negativo diante de uma referência masculina". Dessa forma, observa-se que embora tenha havido várias conquistas, 
as mulheres ainda continuam sendo subjugadas, diminuídas socialmente, e muitas ainda não se reconhecem como o "outro" em sua alteridade, dotadas de direitos de igualdade.

Houve transformações muito importantes nas expectativas sociais ligadas aos papéis de gêneros, conquistas como: o uso das pílulas anticoncepcionais, divórcio, ampliação de leis com garantias de denúncias de violência sexual e doméstica, trabalho remunerado e representatividade no meio político. Contudo, essas transformações estão distantes de uma definição de igualdade social entre homens e mulheres.

Segundo Beauvoir (1970, p. 16) "no momento em que as mulheres começam a tomar parte na elaboração do mundo, esse mundo em sua realidade concreta é um mundo que pertence aos homens". Faz-se inferência de que os homens ainda continuam dominando os meios sociais e políticos, nos quais muitas mulheres ainda continuam sendo vítimas de um meio que só oportuniza os homens e os enxerga como um imperativo, que estes podem exercer a sua soberania para tê-las sob seu domínio.

São muitas as mulheres que lutaram e lutam por engajamento político, para que possam inspirar outras mulheres na tomada de posicionamento contra ao machismo. Beauvoir (1970, p. 23) destaca que "todo indivíduo que se preocupa em justificar sua existência se sente impulsionado por uma necessidade de transcender". Portanto, a luta feminina é para que todas as mulheres sejam tomadas pelo espírito de transcendência e, com isso, se reconheçam como sujeito dotado de liberdade e autonomia.

\section{VALOR E VENDA}

Houve muitas transformações importantes no que concerne aos papéis de gênero, porém essas mudanças estão longe de alcançar uma situação de igualdade entre homens e mulheres. O poderio masculino se estabelece desde o casamento, quando as mulheres eram colocadas à disposição do cônjuge para oferecer-lhe uma vida confortável, e em contrapartida elas recebiam um prestígio social por ter obtido um marido.

Ao longo do século $\mathrm{XX}$, as mulheres obtiveram muitas conquistas, entre elas a legislação começou a definir o casamento como uma parceria entre iguais, eliminando o marido como o único tutor e indivíduo dotado de direito. Mas não eliminou uma cultura histórico-social formada que garantia a primazia do marido sobre a esposa. Assim, percebe-se que até os dias atuais o homem tem poder de decidir e selecionar a mulher que está apta a casar e eliminar aquela que está disponível apenas para se divertir. 
Muitas mulheres ainda vivem em um âmbito social onde são obrigadas e devem total obediência ao homem, seja ele primeiramente o pai ou posteriormente o marido. De acordo com Filmer (1991, p.192) "a soberania dele sobre ela seria natural, determinada pelo fato de ele ser o agente mais nobre e principal da geração". Com isso, forma-se uma hierarquia entre os gêneros, na qual os homens estarão sempre no topo da pirâmide e as mulheres abaixo, formando uma relação de senhor e súdita.

A desigualdade entre os gêneros submeteu a mulher a uma condição de vulnerabilidade, em que os direitos, a situação financeira e a posição social feminina, sendo inferiores em relação aos dos homens determinam uma submissão voluntária das mulheres, na qual muitas se sujeitam às relações por dependência social e financeira.

A dependência da mulher ao homem demonstra duas faces do sexismo. Uma, a superioridade masculina sobre a vulnerabilidade feminina. No que define Pateman (1988, p. 27), “o patriarcado moderno é definido não pela soberania de um indivíduo, mas pela igualdade entre os homens e sua soberania coletiva sobre as mulheres". Outro indicativo que demonstra a soberania masculina é o contrato de casamento firmado na ideia de que a mulher não pode ficar solteira, expressões como "vai ficar pra titia", "passou da idade de casar" e "não casou porque nenhum homem quis", admitem a ideia de que a sociedade enxerga a mulher como dependente do homem e injeta essa ideia na educação de muitas meninas, tornando-as vulneráveis e dependentes do homem para ascender socialmente.

Segundo Pateman (1985, p. 5) "os mecanismos de submissão voluntária é um dos eixos centrais do contrato sexual, no qual as mulheres são convocadas a consentir 'livremente' com a dominação masculina”. Percebe-se isso ao comparar a posição de um trabalhador com a de uma dona de casa, que podem abrir mão de uma boa parte de seus direitos e sua autonomia, em troca do salário ou da proteção física e financeira do marido. Nesses casos, são firmados contratos de compra e valor: o patrão consegue um funcionário disposto a realizar suas tarefas com o mínimo de direitos garantidos e que recebe em troca um bom salário pelo seu silêncio e gratidão; a mulher conquista um marido que lhe oferece os bens necessários para sua sobrevivência física e social e lhe oferece obediência e serviços domésticos de qualidade, na ideia de boa mãe e boa esposa. Em ambos os casos, vê-se uma noção de dominação de classe, na qual, o indivíduo mais vulnerável por questões financeiras ou histórico-sociais se torna o objeto de compra que é submetido ao mais forte.

As relações contratuais são focadas em mecanismos de exploração; assim como o trabalhador precisa vender sua força de trabalho, há mulheres que se sujeitam a vender sua 
autonomia pra ser a "dona de casa perfeita", ou há mulheres que se sujeitam a vender o corpo para receber um valor que pague a sua situação de vulnerabilidade econômica. A respeito do que afirma Nozick (1974, p. 331): "a liberdade precisa incluir o direito de se vender como escravo".

O mesmo ambiente que força a mulher a se casar é o mesmo ambiente que força a mulher a se prostituir. De acordo com Beauvoir (2019, p. 364), "do ponto de vista econômico, a situação da prostituta é simétrica à da mulher casada, entre aquelas que se vendem por prostituição e aquelas que se vendem pelo casamento, a única diferença é o preço e a duração do contrato".

Numa perspectiva freudiana, segundo Pateman (1988) as mulheres não são personagens, são objetos de luta entre os homens; visto isto, a mulher casada é submetida a uma relação de propriedade e, sendo a legítima, é oprimida enquanto casada e respeitada perante o meio social, enquanto que a prostituta é dona do desejo sexual e objeto de demonstração do domínio masculino sobre a mulher, sendo mal vista socialmente e excluída do casamento, pois o homem que a consome é o mesmo que a prende numa escravidão feminina social.

\section{DO CONSENTIMENTO AO EMPONDERAMENTO}

A sociedade ainda carrega a naturalização da dominação masculina, mesmo que seja de maneira inconsciente; são muitos os exemplos diários de submissão da mulher ao homem, como também ainda são fortes as cobranças sociais de gênero. De acordo com Freyre (2005, p. 5), "numa sociedade marcada e fundada com base no patriarcalismo, o machismo ainda se sobressai como forma de dominação natural". Com base nisso, percebe-se que as regras masculinas têm raízes fortes numa sociedade que estigmatiza a mulher que não se rende à plena obediência ao homem.

A luta feminista começou a crescer no século XIX através do Movimento Sufragista, quando muitas mulheres passaram a cobrar as suas posições políticas através do direito ao voto; embora houvesse uma cultura histórico-social enraizada de submissão e inferioridade na educação das meninas, esse foi o primeiro passo para a criação de uma resistência frente à soberania masculina.

No contexto histórico as transformações foram ocorrendo ao longo do tempo, e as mulheres começaram a obter alguns direitos, como posições no mundo do trabalho, acesso a 
remuneração salarial, domínio sobre o seu próprio corpo, garantias legais de segurança sobre violência doméstica e sexual. Porém, Montenegro (1981, p. 32) destaca que "a igualdade de direitos formais foi em parte realizada, mas não era suficiente para assegurar às mulheres direitos iguais na vida real". Com isso, vê-se que a desigualdade de gênero está longe de ser cessada e que as mulheres não conquistaram a sua autonomia social por completo.

É marcante a desigualdade entre os gêneros em diversos espaços fundamentais que minimizam a mulher como ser dotado de direitos e as coloca numa situação de vulnerabilidade. Tais diferenças separam o grupo feminino entre aquelas que se submetem à obediência, seja do lar ou sexual, e aquelas que se encorajam e tomam a frente da luta contra o sexismo, na qual é crescente a representatividade de figuras femininas na política e na causa feminista.

Segundo análise feita por Bordieu (2002, p. 6), "uma das maiores conquistas e mudanças que o feminismo possibilitou foi permitir que a dominação masculina deixasse de ser algo indiscutível”. O movimento feminista se tornou uma luta das mulheres pelas mulheres, um enfrentamento contra a segregação de gêneros, uma luta pela diminuição da situação de vulnerabilidade e dependência de muitas mulheres, para que elas se emancipem e conquistem os seus espaços.

Além do mais, o feminismo foi de extrema importância na inserção da mulher no meio social, possibilitando-lhes o reconhecimento como agentes necessários na sociedade e na história. Afirma Silva (2009, p.146): “assim foram sendo organizados grupos de reflexão nos quais as mulheres compartilhavam seus dissabores, e o que antes parecia ser um problema individual tornava-se coletivo". Desse modo, o empoderamento foi permitindo que muitas mulheres fizessem outras enxergarem o meio em que estão inseridas e as fez enxergar a imposição masculina a que são submetidas, transformando-as em sujeitos na construção de sua própria história, e a união feminina provocou uma verdadeira revolução na elaboração de uma sociedade igualitária entre os gêneros.

\section{REFERÊNCIAS}

BEAUVOIR, Simone de. O segundo sexo: fatos e mitos. Tradução Sérgio Milliet. 4. ed. São Paulo: Difusão Europeia do Livro, 1970.

BEAUVOIR, Simone de. O segundo sexo: a experiência vivida. Tradução Sérgio Milliet. 5. ed. Rio de Janeiro: Nova Fronteira, 2019

BORDIEU, Pierre. A dominação masculina. Rio de Janeiro: Bertrand Brasil, 2002. 
FILMER, Robert. Observações sobre a origem do governo, em Patriarca e outros escritos. Cambridge, Cambridge University Press, 1991.

FREYRE, Gilberto. Casa-grande \& senzala, 50. ed. Global Editora. 2005.

MONTENEGRO, Ana. Ser ou não ser feminista. Recife: Guararapes, 1981.

NOZICK, Robert. Anarquia, Estado e utopia. Nova York: Basic Books, 1974.

PATEMAN, Carole. O contrato sexual. Stanford: Stanford University Press, 1988.

PATEMAN, Carole. O problema da obrigação política: uma crítica à teoria liberal. Reedição com novo posfácio. Berkeley, CA: University of California Press, 1985.

SILVA, Kalina Vanderlei; SILVA, Maciel Henrique. Dicionários de conceitos históricos. São Paulo: Contexto, 2009. 